\title{
INFLUÊNCIA DAS FÁBRICAS DE FERTILIZANTES NA COMPOSIÇÃO DAS ÁGUAS DA CHUVA E SUBTERRÂNEA (RIO GRANDE, RS).
}

\author{
GARCIA, M.R.D.*; MIRLEAN, N.; CASARTELLI, M.R. \& P.R. BAISCH \\ Laboratório de Oceanografia Geológica /Fundação Universidade Federal do Rio \\ Grande \\ Av. Itália, km 8, Cx. Postal 474, Rio Grande, RS-CEP 96200-900 \\ e-mail: marinareback@bol.com.br / dgeonmir@super.furg.br \\ * bolsista CNPq/PIBIC
}

\begin{abstract}
RESUMO
A concentração de fluoreto foi determinada, através do método potenciométrico, com eletrodo íon seletivo, na água da chuva e na água subterrânea, no município de Rio Grande. Os teores de fluoreto na água da chuva variaram de 0,05 a 4,40 ppm, enquanto que na água subterrânea as concentrações de fluoreto variaram entre 0,08 e 2,20 ppm. Os resultados mostram que os teores de fluoreto na água da chuva coletada no ponto de amostragem está relacionada à direção do vento e aos parâmetros de chuva ( $\mathrm{pH}$ e condutividade). Mesmo em regiões mais afastadas das fábricas ( $10 \mathrm{~km}$ de distância), as concentrações de fluoreto podem atingir valores que superam muitas vezes o teor de background mundial para águas de chuva, apresentando forte evidência do efeito das atividades industriais realizadas nas fábricas de fertilizantes. As concentrações de fluoreto nas águas subterrâneas mostram uma tendência de diminuição com afastamento das fábricas.
\end{abstract}

Palavras-chave: precipitação úmida; fluoreto; indústria de fertilizantes.

\section{INFLUENCE OF FERTILIZER PLANTS EMISSIONS IN HUMID DEPOSITION AND GROUND WATER COMPOSITION (RIO GRANDE, RS)}

\begin{abstract}
Fluoride concentration was determined by potentiometric method in rainwater and in groundwater at Rio Grande city. In rain water, the range of fluoride concentration was $0.05-4,40$ $\mathrm{ppm}$, and in ground water it was $0,08-2,20 \mathrm{ppm}$. It was concluded that fluoride concentration in rainwater has relation to wind direction and rain parameters ( $\mathrm{pH}$ and conductivity). Up until distant places from the factories $(10 \mathrm{~km})$, the fluoride concentration in rainwater can be several times higher than those found in seawater, showing a great evidence of the fertilizer factories effect. Groundwater fluoride concentrations demonstrated a tendence of decreasing while the distance from the factories increased.
\end{abstract}

Keywords: humid precipitation; fluoride; fertilizer factories.

\section{INTRODUÇÃO}

As atividades industriais realizadas nas fábricas de fertilizantes são conhecidas, em todo o mundo, como geradoras de efluentes contendo uma larga gama de compostos quí- micos. As emissões atmosféricas lançadas por estas fábricas podem conter compostos nitrogenados (amônia, óxidos nítrico e nitroso, aerossóis de sais de amônia); óxidos de enxofre; vapores ácidos; elementos radioativos; poeira de fertilizante e fluoretos sob a forma de 
$\mathrm{HF} \mathrm{e} \mathrm{SiF}_{4}$ (UNEP, 1998). Um dos poluentes mais característicos dessas indústrias são os fluoretos, resultantes da conversão de rochas fosfatadas em fertilizantes. Esse poluente é lançado no ambiente em concentrações bastante significativas, influenciando fortemente a composição química dos sistemas naturais no entorno dos pontos de emissão.

Dependendo do aporte antrópico e da concentração nos segmentos do meio ambiente, o fluoreto pode causar muitos efeitos deletérios. É possível ocorrer sérios danos aos animais, às plantas e também ao homem (Manahan, 1993; O'Neil, 1993). Ao ser assimilado pelos organismos, este elemento provoca efeitos tóxicos, pois interfere em sistemas enzimáticos e em muitos processos endócrinos. Desta forma, há prejuízos ainda pouco conhecidos para os sistemas ecológicos afetados. Além disso, quando presentes na atmosfera, os fluoretos podem causar também danos materiais, tendo como exemplo a corrosão do vidro em instalações elétricas de alta tensão.

Há registros de efeitos negativos da poluição por fluoreto em Rio Grande, tais como casos de fluorose bovina (Riet-Corrêa et alli, 1983); danos à vegetação (Nunes, 1979) e corrosão em isoladores de vidro da rede de alta tensão (Brigoni, 1983). Nesses estudos, as fábricas de fertilizantes instaladas no município foram apontadas como principais fontes de fluoreto à atmosfera local. O parque industrial da cidade de Rio Grande conta, atualmente, com quatro unidades de produção de fertilizantes. No entanto, até a presente data, nenhuma pesquisa foi realizada na região sobre a distribuição deste poluente nos componentes ambientais da região, pode ser referido apenas um estudo de modelagem matemática da possível distribuição de fluoretos totais na atmosfera da cidade e distrito industrial (Brigoni, 1983).

O objetivo do presente estudo é avaliar a contaminação por fluoreto na água da chuva e na água subterrânea da cidade de Rio Grande, relacionando com as características das águas, as condições atmosféricas e a distân- cia dos pontos de amostragem às principais fontes de poluentes.

\section{MATERIAIS E MÉTODOS}

Amostragem de precipitação líquida: as amostras de água da chuva foram coletadas em um ponto localizado em uma área aberta $e$ afastada dos centros urbanos e industrial (Figura 1). Foi utilizado um coletor em forma de funil de polipropileno ( $17 \mathrm{~cm}$ de diâmetro), instalado a 6,0 metros da superfície do solo, 1,0 metro acima do telhado do pavilhão do laboratório, no Campus da Universidade. À sua saída foi conectada uma mangueira, que conduzia a água da chuva para um sistema de fracionamento, composto por três balões volumétricos de $25 \mathrm{ml}$, conectados em série por mangueiras. Este sistema permite a coleta fracionada de três parcelas de chuva, cada uma correspondendo a $1 \mathrm{~mm}$ de precipitação. Cada balão era fechado automaticamente por uma esfera plástica, após ser preenchido, evitando desse modo a mistura entre as parcelas. Depois de completado o volume desses balões, a água da chuva passava a ser recolhida em um frasco plástico com capacidade aproximada de 3 litros (4⿳亠丷厂 parcela restante de chuva). Todos os componentes do coletor foram cuidadosamente limpos antes de cada amostragem. Foram amostrados 38 eventos de chuva (parceladas em 124 amostras de água), no período de outubro de 1998 a julho de 1999.

Amostragem de água subterrânea: em cada ponto de amostragem perfurou-se o solo, com o auxílio de um cano de PVC, até encontrar o nível do lençol freático (aproximadamente $1 \mathrm{~m}$ ). Esse tipo de procedimento foi facilitado em razão da natureza arenosa e pouco compactada do solo da região. A água subterrânea foi extraída com uma bomba a vácuo manual (Nalgene) conectada por mangueiras de silicone a um frasco coletor. $\mathrm{Na}$ entrada do frasco, foi adaptada uma malha de porosidade de $63 \mu \mathrm{m}$, para evitar a mistura com areia. Foram realizadas quatro amostras durante a primavera de 1999 (Figura 1). 
Procedimentos analíticos: cada fração de água da chuva ou de água subterrânea foi filtrada em membranas Millipore $(<0,45 \mathrm{~mm})$ e, logo após, foram realizadas em laboratório as leituras de $\mathrm{pH}$ (eletrodo marca Analion, acoplado a um pHmetro Accumet, modelo n.15) e condutividade (condutivímetro marca Oaktron, modelo WD-35607-10). As análises de fluoreto foram realizadas no mesmo dia da coleta, pelo método potenciométrico, utilizando-se um eletrodo para fluoretos da Orion, modelo 96-09, seguindo as especificações do fabricante (Orion, 1991). Como TISAB, foi preparada uma solução de ácido acético e cloreto de sódio, com pH ajustado entre 5,0 - 5,5 com solução de hidróxido de sódio. As leituras em $\mathrm{mV}$ dos

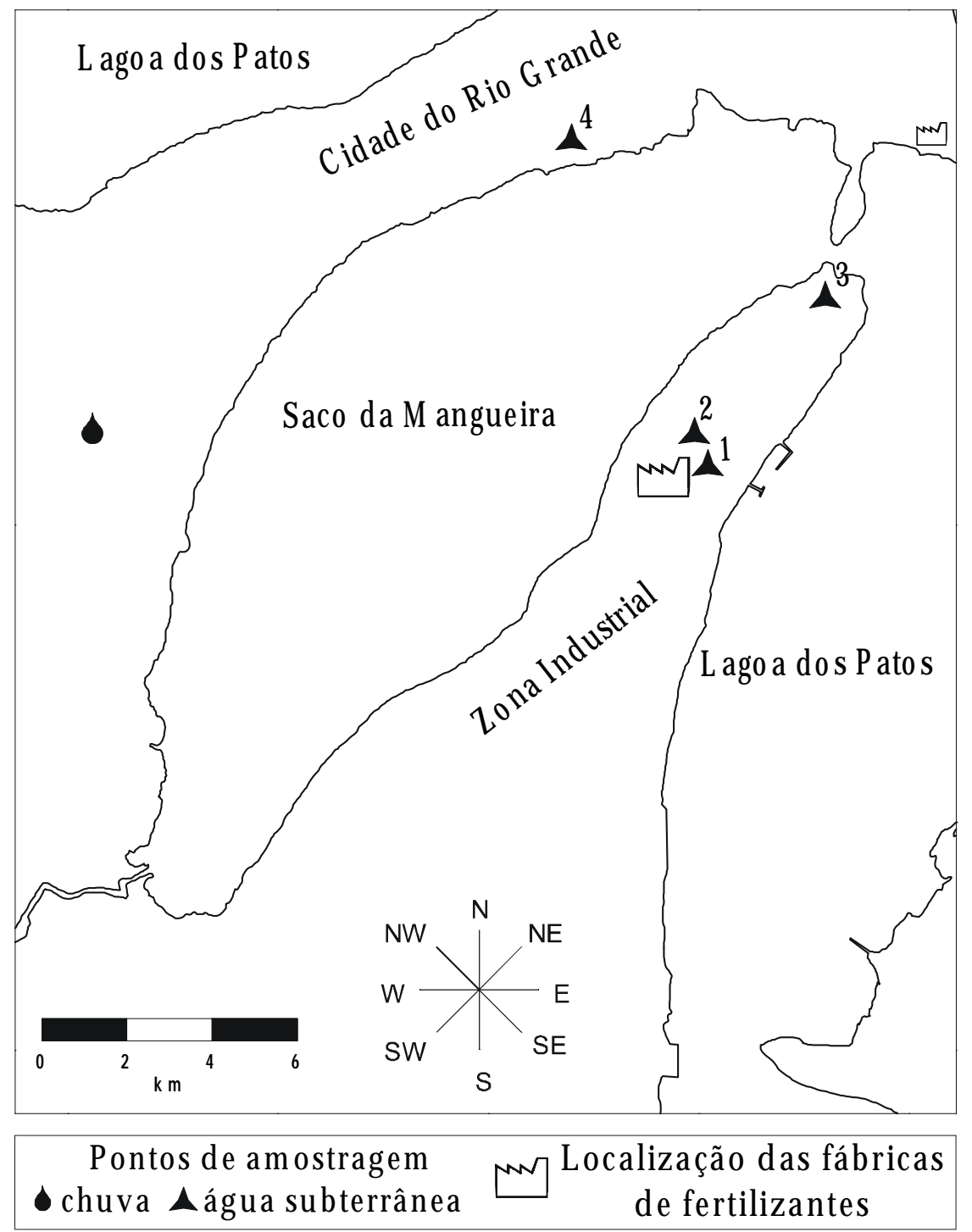

Figura 1: Localização dos pontos amostrais e das principais fontes de fluoreto na atmosfera (fábricas de fertilizantes) 
padrões foram plotadas em função das concentrações e, a partir da curva padrão obtida, determinou-se a concentração de cada amostra.

\section{RESULTADOS}

O flúor presente nas partículas sólidas na atmosfera é lixiviado rapidamente pelas precipitações atmosféricas. Por isso, a concentração de fluoreto na primeira parcela de chuva representa a poluição da atmosfera, no momento do evento de chuva, sobre o ponto de coleta. Com a continuidade do evento da chuva, verifica-se que ocorre uma forte redução da concentração de fluoreto na água da chuva (Figura 2). Nas primeiras parcelas da chuva, as concentrações variam de 0,05 a 4,40 ppm, e a média é de 0,42 ppm $( \pm 0,75)$. Nesta região, consideramos como nível de background para a água da chuva os valores médios de fluoreto $(0,08 \pm 0,05 \mathrm{ppm})$ referentes à quarta parcela da chuva (26 amostras), que corresponde aproximadamente $95 \%$ do volume total das precipitações. Esse valor supera em quase duas vezes o valor de background mundial (Drever, 1982).

O valor da concentração de fluoreto na água da chuva não excede 1,0 ppm na primeira parcela de 34 eventos de chuva. Valores de concentração de fluoreto acima de 1,0 ppm são

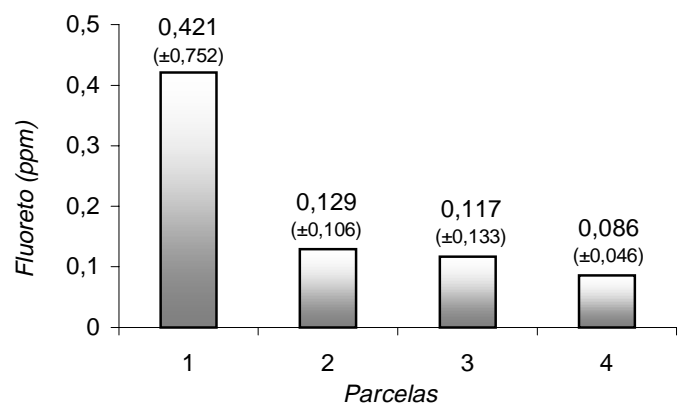

Figura 2: Média e desvio padrão das concentrações de fluoreto- em cada parcela de chuva $(n=38,31,29$ e 26, nesta ordem). encontrados na primeira parcela somente em quatro eventos. Para as amostras com concentrações de fluoreto menores que 1,0 ppm, podem ser determinadas algumas relações entre as concentrações de fluoreto com pH e condutividade da água da chuva (Figura 3). Constatou-se que a concentração de fluoreto eleva-se com o aumento de $\mathrm{pH}(r=0,507$; $p=0,01)$ e da condutividade $(r=0,473 ; p=0,01)$.

As chuvas com concentração de fluoreto maior que 1 ppm apresentam outras características. As concentrações encontradas foram de 1,15 ppm (duas vezes), 1,48 ppm e 4,40 ppm. Essas amostras apresentaram caráter ácido ( $\mathrm{pH}$ entre 3,93 - 5,55) e condutividade baixa (122,3 - 171,4 mS.cm $)$ em relação aos valores obtidos nas primeiras parcelas de chuva (Figura 3b). Além disso, verificou-se que a direção de vento para as chuvas com maior concentração de fluoreto é proveniente dos quadrantes $\mathrm{E}, \mathrm{NE}$ e SE, que coincidem com a direção entre as fábricas e o ponto de estudo dos eventos de precipitações atmosféricas. No caso da chuvas que começam quando o vento vem da direção oposta à das fábricas (quadrantes W, NW, SW), isto é, vindo da área continental, apresentam teores máximos de fluoreto que não superam 0,5 ppm $(0,23-0,38$ ppm).

A água subterrânea apresentou valores bastante variáveis dos parâmetros analisados. As concentrações encontradas foram de 1,49 ppm para o ponto 1; 1,77 ppm para o ponto 2; 2,20 ppm para o ponto 3 e 0,08 ppm para o ponto 4 (Figura 1). A média de concentração de fluoreto foi de 1,39 $\pm 0,918 \mathrm{ppm}$. Aparentemente, não há relação entre os valores de $\mathrm{pH}$ $(4,97-7,86)$, condutividade (309-855 mS.cm $\left.{ }^{-1}\right)$ e concentração de fluoreto. É possível observar que a distância em relação às fontes não influenciou proporcionalmente as concentrações de fluoreto, ou seja, à medida que aumenta a distância entre os pontos amostrais e as fábricas não há necessariamente diminuição nas suas concentrações. Pode-se notar que na distância de 2,5Km das fábricas (ponto 4) a concentração de fluoreto na água subter- 
rânea apresentou uma diminuição muito considerável.

\section{DISCUSSÃO}

Devido à área de estudo estar localizada em zona costeira, poderia admitir-se que tanto a distribuição de fluoreto como as características apresentadas pelas primeiras parcelas da chuva deveriam estar relacionadas com a dispersão de sais marinhos. No entanto, este argumento não pode ser comprovado, pois as concentrações de fluoreto encontradas nas águas do mar são próximas de 1,0 ppm e, para que seus teores atingissem ainda valores de 0,5 ppm, a condutividade da água da chuva, deveria apresentar valores muitas vezes maiores do que os encontrados nas amostras analisadas.
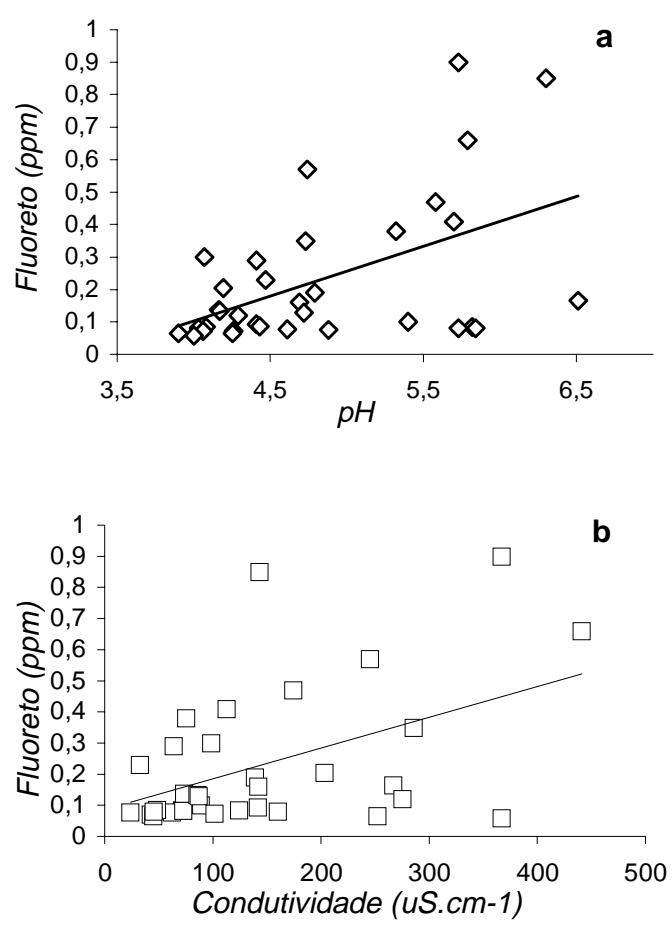

Figura 3: Relações entre concentrações de $\mathrm{F}^{-}$na primeira parcela de chuva com: $\mathrm{pH}$ (a) e condutividade (b), para chuvas com menos de 1 ppm de fluoreto.
Segundo estudos precedentes, as chuvas com alta condutividade e características neutras ou pouco alcalinas são observadas quando o vento nesta região tem direção oposta ao mar, isto é, vem da direção da área continental, do interior do Estado (Mirlean et al, 2000). Então, neste caso, o fluoreto presente na água da chuva em concentrações relativamente altas pode estar relacionado com o uso de fertilizantes nas áreas agrícolas desta região.

No entanto, os dados obtidos com relação às amostras com concentração de fluoreto maior que 1.0 ppm sugerem outra fonte para o elemento químico em questão. Foi mostrada uma clara relação entre o aparecimento de fluoreto na água da chuva e as direções de vento orientadas na direção das indústrias de fertilizante. Desse modo, é possível inferir que as máximas concentrações de fluoreto registradas na água da chuva foram ocasionadas pelas emissões dessas fábricas de fertilizantes e que as mesmas têm caráter ácido.

Com relação à concentração de fluoreto nas águas subterrâneas, esperava-se que a concentração de fluoreto na água do lençol freático diminuísse gradualmente com o aumento da distância das fábricas, refletindo o nível de poluição atmosférica deste elemento. Esse quadro era esperado pois os compostos atmosféricos de flúor são altamente solúveis e os solos desta região (arenosos distróficos) são pobres em matéria orgânica e argilominerais (Cunha \& Silveira, 1995), o que favorece rápida a infiltração das precipitações. Ademais, o lençol freático encontra-se aproximadamente no mesmo nível em toda a área de estudo, devido ao relevo muito baixo e plano e composição dos solos sem variação significativa.

Contudo, o comportamento previsto não se verificou de forma clara. $O$ estudo sobre a distribuição de fluoreto no lençol freático, nas zonas urbanas, representa somente uma linha de tendência, isto é, não permite que se estabeleça a forma da zona de dispersão do poluente no ar atmosférico. No caso aqui estudado, a limitação provavelmente é originada por 
dois fatores. O primeiro seria a ausência de um sistema de canalização de esgotos em grande parte da área urbana, permitindo que os efluentes domésticos penetrem no lençol freático, alterando a concentração de fluoreto nas águas subterrâneas. O segundo seria o fato de que, durante os períodos de estiagem, caracterizados por baixas taxas pluviométricas, o nível do lençol freático diminui e possibilita a invasão de águas do estuário e das lagoas interiores na faixa mais próximas das margens dos corpos d'água. Não é possível ignorar que esses corpos d'água provavelmente estão poluídos por fluoreto pois recebem os efluentes líquidos das fábricas de fertilizantes. Durante o período de estudo, registrou-se 5,0 ppm de fluoreto na água do corpo d'água conhecido como "Saco da Mangueira", situado adjacente à zona industrial da cidade (Figura 1). A atuação conjunta desses dois fatores deve influenciar a composição da água subterrânea nesta região, fazendo com que a concentração de fluoreto neste meio não corresponda à sua distribuição na atmosfera.

\section{CONCLUSÕES}

Este estudo nos mostra que a poluição da atmosfera por fluoreto pode ser atribuída às emissões das fábricas de fertilizantes, que são as principais fontes desse poluente na região. A concentração do fluoreto na água da chuva depende da direção do vento no momento que se inicia a chuva e poluição propaga-se por grandes extensões (a distância das fábricas até o ponto da coleta é de, aproximadamente, $10 \mathrm{~km}$ ).

A precipitação de fluoreto na superfície do solo provoca o aumento dos seus teores nas águas subterrâneas e determina que a sua concentração relacione-se com a distância das fontes de poluição. No entanto, essas concentrações não apresentam uma distribuição da poluição por fluoreto de maneira gradiente, provavelmente devido à influência das emissões de esgotos domésticos e invasão das águas do sistema estuarino.

\section{AGRADECIMENTOS}

Os autores agradecem ao programa de Apoio ao Desenvolvimento Científico e Tecnológico -PADCT/CNPq - as bolsas fornecidas e ao Laboratório de Meteorologia da Fundação Universidade do Rio Grande (FURG) por nos haver cedido os dados de direção de vento.

\section{REFERÊNCIAS BIBLIOGRÁFICAS}

Brigoni, S.F. 1983. Estimativas da qualidade do ar na Cidade de Rio Grande. Relatório Interno: Depto . do Meio Ambiente, Divisão de Controle de Qualidade do Ar.

Cunha, N.G. \& R.J.C. Silveira. 1995. Geomorfologia e Solos de Rio Grande. CPACT- EMBRAPA, Pelotas.

Drever, J.I. 1982. The geochemistry of natural waters. Prentice-Hall. Inc., N.J.

Manahan, S.E. 1993. Fundamentals of Environmental Chemistry. Lewis Publishers.

Mirlean, N; Baisch, P. \& A. Vanz. 2000. Níveis e origem da acidificação das chuvas na região do Rio Grande, RS. Química Nova.

Nunes, L.A.L. 1979. Relatório preliminar do impacto sobre a qualidade do solo, fauna e flora relativo à implantação do distrito industrial de Rio Grande. Relatório Interno: Dept $^{\circ}$. do Meio Ambiente, Porto Alegre.

Ohlweiler, O.A. 1971. Química Inorgânica. Editora Edgard Blücher Ltda.

O'Neill, P. 1993. Environmental Chemistry, $2^{\text {nd }}$ Ed. Chapman \& Hall.

ORION - Orion Research Incorporated. Instruction Manual, 1991.37p.

Riet-Corrêa et al. 1983. Poluição industrial como causa de intoxicação por flúor em bovinos no município de Rio Grande. Pesquisa Veterinária Brasileira. 3(4)

Thornton, I. 1983. Applied Environmental Geochemistry. Academic Press.

Todd, D.K. 1959. Hidrologia de Águas Subterrâneas. Editora Edgard Blücher Ltda. 
NOTAS TÉC. FACIMAR, 4: 29-35, 2000.

UNEP - United Nations Environment Programme Industry and Environment, 1998. Mineral fertilizer production and the environment: the fertilizer industry's manufacturing procecess and environmental issues. Technical Report n. 26, part 1. United Nations Publication. 